\title{
Breathing Aid Devices to Support Novel Coronavirus (COVID-19) Infected Patients
}

\author{
Md. Milon Islam ${ }^{1}\left[\right.$ - Shah Muhammad Azmat Ullah ${ }^{2} \cdot$ Saifuddin Mahmud ${ }^{3} \cdot$ S. M. Taslim Uddin Raju ${ }^{1}$
}

Received: 4 August 2020 / Accepted: 10 August 2020 / Published online: 19 August 2020

(c) Springer Nature Singapore Pte Ltd 2020

\begin{abstract}
Novel coronavirus (COVID-19), an ongoing pandemic, is threatening the whole population all over the world including the nations having high or low resource health infrastructure. The number of infection as well as death cases are increasing day by day, and outperforming all the records of previously found infectious diseases. This pandemic is imposing specific pressures on the medical system almost the whole globe. The respiration problem is the main complication that a COVID-19 infected patient faced generally. It is a matter of hope that the recent deployment of small-scale technologies like 3D printer, microcontroller, ventilator, Continuous Positive Airway Pressure (CPAP) are mostly used to resolve the problem associated with medical equipment's for breathing. This paper aims to overview the existing technologies which are frequently used to support the infected patients for respiration. We described the most recent developed breathing aid devices such as oxygen therapy devices, ventilator, and CPAP throughout the review. A comparative analysis among the developed devices with necessary challenges and possible future directions are also outlined for the proper selection of affordable technologies. It is expected that this paper would be of great help to the experts who would like to contribute in this area.
\end{abstract}

Keywords Novel coronavirus · COVID-19 $\cdot$ Breathing aid · Respiratory support · Oxygen therapy device $\cdot$ Ventilator $\cdot$ Continuous positive airway pressure

\section{Introduction}

This article is part of the topical collection "Advances inComputational Approaches for Artificial Intelligence, ImageProcessing, IoT and Cloud Applications" guest edited by BhanuPrakash K N and M. Shivakumar.

Md. Milon Islam

milonislam@cse.kuet.ac.bd

Shah Muhammad Azmat Ullah

azmat.ece.kuet@gmail.com

Saifuddin Mahmud

smahmud2@kent.edu

S. M. Taslim Uddin Raju taslimuddinraju7864@gmail.com

1 Department of Computer Science and Engineering, Khulna University of Engineering \& Technology, Khulna 9203, Bangladesh

2 Department of Electronics and Communication Engineering, Khulna University of Engineering \& Technology, Khulna 9203, Bangladesh

3 Department of Computer Science, Kent State University, Kent, Ohio, USA
It is announced by the World Health Organization (WHO) that the novel coronavirus (COVID-19) has become a pandemic in recent times. The severity of this pandemic is increased from day to day and created new records almost every day. The infected, death and recovered cases for this disease are $18,514,884,699,027$, and $11,731,138$, respectively, around the world [1]. Due to this pandemic, almost all the sectors including the healthcare system [2] are facing a serious crisis of infrastructure both in developed and developing countries.

There are several types of diseases such as heart disease [3], breast cancer [4, 5], liver disorder [6], diabetes [7] available in medical science that causes a lot of problems in human health but the current pandemic is COVID-19 [8, 9]. The major symptoms for COVID-19 are fever, tiredness, breathing difficulties, and dry cough [10]. Among these symptoms, the respiration problem is more severe and acute [11]. There are crucial devices [12, 13] usually available within the healthcare technology $[14,15]$, but they simply do not occur in a high sufficient density to deal with the 
increased number of patients related to epidemics. Various assistant devices [16-19] are developed to support humanity in different applications like fall detection for elderly [20, 21], staircase detection [22, 23], path hole as well as road surface smoothness detection [24-27], and any types of hindrances detection $[28,29]$ using modern technologies. The recent development of respiratory support systems assists infected patients for initial treatment. Oxygen therapy devices [30, 31] are an appropriate solution for the COVID-19 patients, generally available in hospitals as well as ambulance. Ventilators both invasive and non-invasive are mostly used devices for breathing assistance in the hospital environment $[32,33]$. The recent deployment of CPAP devices $[34,35]$ has emerged a direction for the patients having breathing problem.

The paper aims to overview the recent technologies that are evolved for the COVID-19 infected patients for breathing assistant. The review described breathing aid devices like oxygen therapy devices, ventilators, and CPAP devices. The developed systems are demonstrated in terms of the working principle, the construction procedure, the used hardware components, cost analysis, and comparative advantages and disadvantages. To find the best technology, a comparative analysis among the available devices with challenges and possible future trends are outlined in the review.

The rest of the paper is organized as follows. Section "Breathing Aid Devices for COVID-19 Patients" describes the existing technologies for breathing support for the patients infected with COVID-19. A relative analysis among the available technologies with the necessary challenges and possible future directions are described in Section "Discussions". Section "Conclusion" concludes the paper lastly.

\section{Breathing Aid Devices for COVID-19 Patients}

Breathing aid devices are used to support the patients who have acute respiration problem due to pneumonia associated diseases like COVID-19, asthma, and dry coughing. The most used devices which are utilized for COVID-19 treatment are oxygen therapy device, ventilator, and CPAP device. The possible categorization is shown in Fig. 1 for easy understanding.

\section{Oxygen Therapy Device}

Oxygen gas which is found in the air is necessary for human life for breathing. While one feels short of breath and the level of oxygen being very low than supplemental oxygen, oxygen therapy is needed as a breathing aid. Oxygen therapy is generally received using tubes wearing in nose or trachea, face mask, or windpipe. From various kinds of oxygen therapy, direct oxygen gas, or liquid stored in a portable tank is used widely all over the world. Besides, oxygen concentrators that take oxygen from the room and another device named hyperbaric oxygen therapy in which oxygen gas is pressurized in a room or chamber are used mostly. Though oxygen has a fire risk, this therapy is normally safe and can improve survival rates [36]. Oxygen therapy can play an important role in COVID-19 patients like other breathingrelated diseases including pneumonia and asthma.

Oxygen therapy by nasal cannula is a well-known procedure in controlling and preventing respiratory diseases like COVID-19. It provides 5-6 L of oxygen flow per minute [37]. In the nasal cannula system, a small amount of air is continuously vacuumed and transferred to a sensor located on the display [38]. A face mask is also used as an oxygen serving system. This mask is fitted with one unidirectional valve for inspiration and two unidirectional valves for expiration. A high oxygen flow is provided to the mask continuously that dilutes the carbon dioxide exhaled by the patient [39]. There are two types of face mask which are used to deliver inspired oxygen $\left(\mathrm{FiO}_{2}\right)$ flow. Non-Rebreathing Mask (NRM) provides supplemental oxygen with the rates of approximately 5-10 L/min; while, Partial Rebreathing Mask (PRM) can provide a flow rate of $90 \%$ of $15 \mathrm{~L} / \mathrm{min}$ [40]. Farias et al. [41] described a system in their study that PRM can deliver high oxygen flow than NRM. Nasal cannulas and face masks can be used for COVID-19 patients in low-risk cases. In serious respiratory failure, high-flow
Fig. 1 Breathing assistant available for COVID-19 infected patients

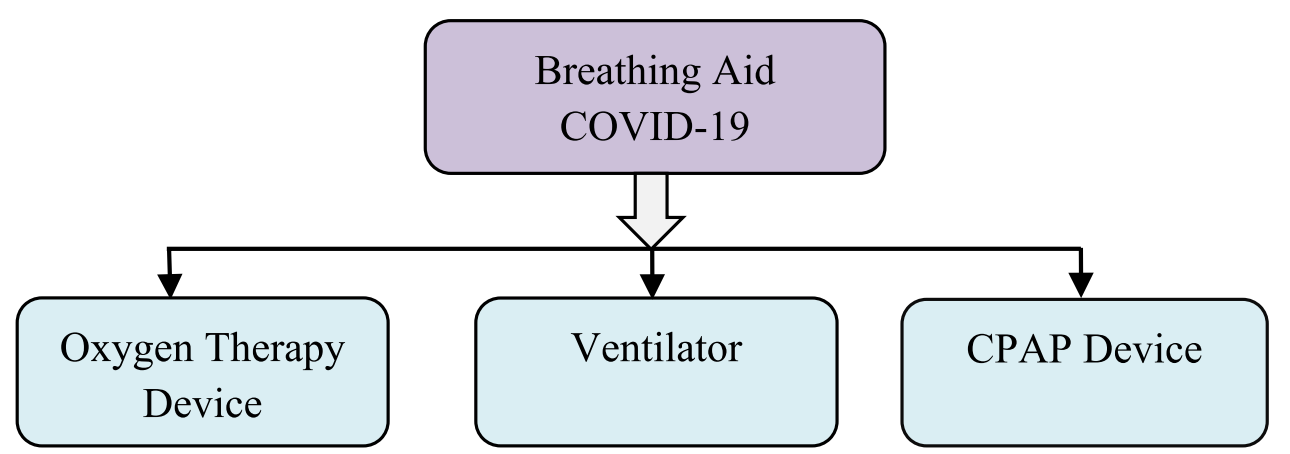


nasal cannula (HFNC) is used for its safety and efficacy. It consists of an air/oxygen blender, a nasal cannula, a single heated tube, and an active humidifier [42]. It can deliver about $60 \mathrm{~L} / \mathrm{min}$ oxygen flow. The use of HFNC limited the mortality in hypoxemic respiratory failure. In addition, it can decrease the risk of subsequent intubation and the need for Intensive Care Unit (ICU) admission [43-45]. It can be commonly used in COVID-19 patients having respiratory failure as a method to administer high concentrations of oxygen.

Another type of oxygen serving device is Hyperbaric Oxygen Therapy (HBOT) [46] in which patients are entered in a special chamber or room to breathe in $100 \%$ oxygen in air pressure. The target of this device is to repair and restore normal body function by filling the blood with adequate oxygen. Air pressure is raised 1.5-3 times from the normal air pressure in a hyperbaric oxygen treatment chamber. In such circumstances, patients' lungs could collect more oxygen than normal air pressure to breathe pure oxygen. This oxygen transports blood all over the body. This helps to kill bacteria and encourages the release of cures of substances such as growth factors and stem cells. There are two types of HBOT (1) Monoplace chamber, (2) Multiplace chamber. Monoplace unit is designed for one person where the patient lies down on a table. It is like a Magnetic resonance imaging (MRI) machine with a long plastic tube. With $100 \%$ oxygen, it is slowly pressurized. In contrast, a room designed for several persons is called multiplace chamber. This chamber usually looks like a large room in the hospital where a patient can sit down or lie down. In this case, the oxygen is normally supplied with a thin, transparent hood. Though this therapy is normally a safe procedure, it carries some risk. In certain situations, fire may trigger due to the oxygen-rich atmosphere in the treatment chamber. In addition, a lung may collapse due to certain changes in air pressure [47, 48]. A recent study [49] shows that using additional oxygen up to certain concentrations can improve mortality in certain populations. The oxygen therapy devices which are frequently used are shown in Fig. 2.
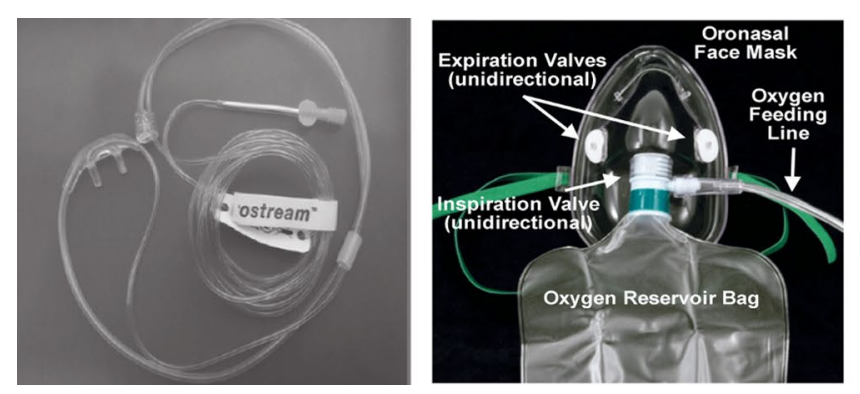

\section{Ventilator}

Ventilator known as a mechanical ventilator is widely used as a breathing aid tool while a disease makes the respiration difficult or can not bring enough oxygen into the blood. It works like a bellow for moving air in (oxygen) and out (Carbon Dioxide) of the lungs. It can be fitted with a mask, a helmet, or a breathing tube if the respiration problem is more serious to get air into the lungs. The major advantages of the use of a ventilator are no trouble occurs in respiring because the muscles are relaxing in the patients' breathing. In addition, the patient will recover from the failure of normal breathing. Ventilators can play a significant role for COVID-19 patients having acute respiratory distress syndrome (ARDS) and pneumonia.

Recently, a new high-pressure ventilator called Ventilator Intervention Technology Accessible Locally (VITAL) is developed by NASA engineers which is approved by the Food and Drug Administration (FDA) for emergency treatment of COVID-19 patients [50]. Like other ventilators, this ventilator also requires sedation in patients and insertion in their airways of an oxygen tube to breathe. Before the FDA review, on 21 April at the Icahn School of Medicine at Mount Sinai, NY, a critical test was performed with the VITAL prototype. The important benefit of this device is it can be faster designed and easier to maintain than a conventional ventilator and consists of far fewer components. "AmboVent" [51] is the bag valve mask (BVM)-type ventilator that provides breathing speed, volume controls, and maximum peak pressure controls of an emergency patient. It is normally used in an ambulance. This device is developed with a Volume control ventilation (VCV) machine, BVM, Positive end-expiratory pressure (PEEP) adapter, PEEP valve, Heat and moisture exchanger (HME) filter, oxygen reservoir bag. The main features of this device are it has a big range of tidal scale, varying from 30 to $100 \%$ of maximum tidal capacity, and large rates of ventilation of 6-24 cycles per minute. MIT Emergency Ventilator (E-Vent) [52], which is formed on March 12, 2020, designed a simple ventilator in response to the rapid spread of the COVID-19
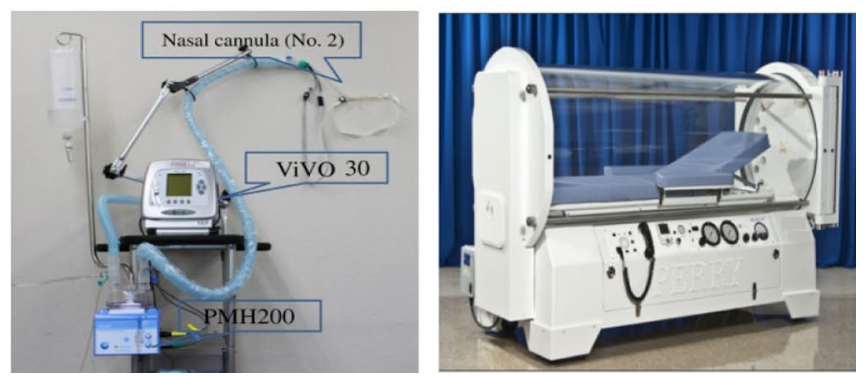

Fig. 2 Typical oxygen therapy devices for breathing support. a Nasal Cannula [38], b NRM [39], c HFNC [42]. d Hyperbaric oxygen therapy [46] 
pandemic. This new system fits into an Ambu bag that is already used in many hospitals. These types of bags are designed to be manually operated by a doctor or emergency nurse in circumstances such as a heart attack to breathe of a patient. But in MIT E-Vent, a mechanical system is developed to perform squeezing and releasing of the Ambu bag. This leads air through a tube in the airway of the patient. The developed device is very reliable and handled manually immediately.

Lu et al. [53] designed a portable high-frequency ventilator which is low cost, portable, and light weight. Here, advanced technologies of electronics and mechanical are integrated throughout the work. As a mechanical instrument, two check valves, two flow meters, two flow control valves, one pressure sensor, one solenoid valve, and one gas chamber are used to regulate the airflow. Multiplexer, comparator, oscillator, capacitor, Digital to Analog (D/A) converter, MOSFET, and voltage converter are utilized as electronic instrument in the control circuit board to control the frequency. The measurable parameters of this device are shown on a digital display as flow per minute $(0-40 \mathrm{~L} / \mathrm{min})$, output frequency $(2-4 \mathrm{~Hz})$, oxygen concentration flow per once $(0-160 \mathrm{~mL})$. The main advantages of this device are its small size, configurable features, and instant feedback control. Using the concept Artificial Manual Breathing Unit (AMBU) bag, Shahid [54] proposed a cost-effective prototype of a ventilator. The main components of this prototype are microcontroller, pressure sensor, breath detection elements (Thermistor and $\mathrm{CO}_{2}$ sensor), and mechanical mechanism (chained plank mechanism and cam shaft mechanism). Moreover, the key features of this prototype are that various parameters like Breaths Per Minute (BPM), delivered air volume by this ventilator, peep rate and inspiration to expiration ratio can be regulated or adjustable. The considerable cost of this proposed prototype is less than $\$ 80$.

Islam and Ahmad [55] developed a microcontroller-based mechanical ventilator using BVM ventilation mechanism and AMBU bag. Here, this AMBU bag is operated (compressed and decompressed) with computer-aided manufacturing (CAM) arm which is controlled via a control signal sent from microcontroller. The main merits of this device are its portability, compact design, light weight, and easily performable. This repairable and riskless device serves $90 \%$ accuracy in respiratory measurement. Jürß and Degner [56] described a concept of compact and low-cost ventilator having the blower unit and an integrated sensor unit. The key feature of this study is that without any respiration tubes, the proposed device can provide necessary ventilation to the patient's lungs with the blower unit. In addition, the relevant respiration data can be monitored with the sensor unit. In another work, a low-cost ventilator is proposed by Garmendia et al. [57]. The major components of the developed system are Arduino Nano as a controlling device, high-pressure blower, and two pressure transducers. This non-invasive high commercial device is low cost as the authors declare the fabrication cost is less than $\$ 75$. Further, a portable ventilator is described in [58] based on BVM and cam arm operated by an electric motor. Though it serves a short time solution, it delivers the essential features of conventional ventilators at low cost, low power, and easy portability. The estimated price of manufacturing this device is less than \$200. A prestage public access ventilator (PAV) [59] is designed with a turbine and sensors. The developed prototype can detect leakage and airway occlusion using the signals from sensors. The PAV was verified under three conditions 1) pressure-controlled ventilation (PCV), 2) PCV with controlled leakage and 3) PCV with simulated airway occlusion. Also, there a proposal is available for Cardiopulmonary resuscitation (CPR) victim by Fogarty et al. [60] using an electric blower ventilator in replace of traditional BVM. The proposed work can reduce the chance of injury from ventilation of the BVM. The available ventilators for breathing assistant are shown in Fig. 3.

\section{Continuous Positive Airway Pressure (CPAP)}

Continuous Positive Airway Pressure is a well-known device that is used for breathing assistant for the treatment of patients having a mild respiratory problem. The positive airway pressure is delivered through a tight face or nasal mask in CPAP device. The main advantage of CPAP device is that it can deliver positive pressure in each cycle of respiration.

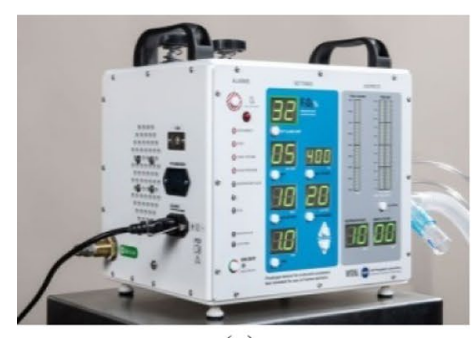

(a)

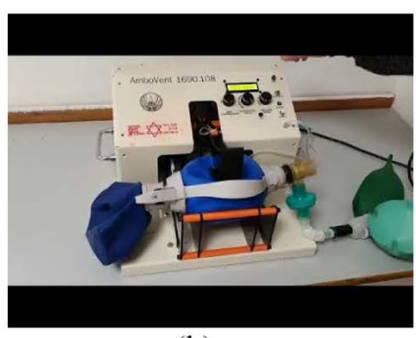

(b)

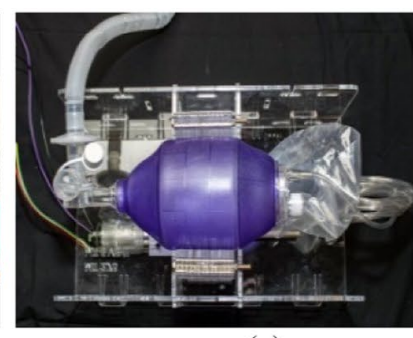

(c)

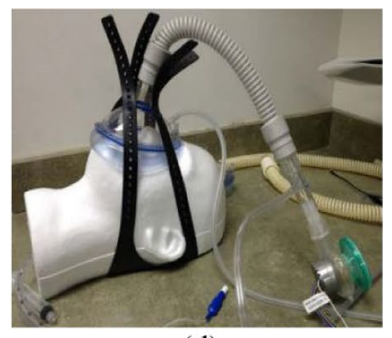

(d)

Fig. 3 Ventilators for breathing assistant. a VITAL [50], b AmboVent [51], c MIT E-Vent [52], d electric blower Ventilator [60] 
The pressure facilitates the alveoli to remain open during the breathing out of patients that is very helpful for oxygenation and easy breathing. The device is proper suited for the patients having pneumonia related problems like COVID-19 for initial treatment.

There are several CPAP devices already developed for breathing aid of the coronavirus infected patients. A lowcost, microcontroller controlled electro-mechanical device is developed in [61] for the respiratory support of COVID-19 infected patients. The developed system consists of a control unit, a power supply with battery backup, a digital display (LCD), an air pump, and a nasal mask. The main unit is here the air pump that is utilized for making pressurized air. The current cost of the developed prototype is approximately $\$ 140$. An open-source breathing aid device is under development in [62] which is low cost. The developed system used an Arduino Nano as a microcontroller, DC motor, power supply, inflator pump, facial mask, and some 3D-printed parts. The considered cost of the prototype is about $\$ 20$. However, the prototype is not recommended for medical applications due to the lack of enough tests with targeted people. In another research, a bubble CPAP is introduced that provides a combined oxygen supply and space air to the respiratory-depressed babies [63]. The developed system is a cost-effective device with high durability and provides easy-to-use facility with a simple design. Dundek et al. [64] developed a low cost bubble CPAP with the use of limited resources. The main component which is used here is an air blender where pressurized oxygen is delivered as input and the output is the combination of air and oxygen. The prototype was developed with the combination of several parts printed in a $3 \mathrm{D}$ printer. Although the actual cost is not mentioned here, it is noted that the cost is $1 \%$ less than the gold standard device. Gehlot et al. [65] introduced a multi-power breathing aid device named as 'Saans' for the infants having severe respiration problem. The prototype is comprised of battery-powered air pump, bubble jar, heated humidifier, and resuscitation circuit. The developed device is tested with targeted people (newborn baby). Further, Mukkundi et al. [66] proposed a multi-powered CPAP device for respiratory support for the patients having a breathing problem. In this system, two flow meters are used to control air and oxygen. The prototype is cost effective and easy to use. The developed system is tested in a real-time environment and achieved reasonable output. The popular CPAP devices that are extensively used or under development are shown in Fig. 4.

\section{Discussions}

In this review, a comparative analysis among various breathing assistant devices supporting the COVID-19 pandemic situation is described. All of the necessary features of the reviewed technologies are depicted in Table 1.

Among the reviewed systems, ventilators and CPAP devices are comparatively low cost. Some study shows their cost less than $\$ 100$ in $[54,57,62]$ and higher than $\$ 100$ in $[58,61]$. In contrast, oxygen therapy has a relatively higher cost than others [46]. Similarly, both ventilator and CPAP are light weight $[53,55,58]$ where oxygen therapy device has heavy weight as it consists of many complex parts [48]. Except medical technologies, there are several technologies that are used to develop these devices such as microcontroller, CAM, electronics, and mechanical. Arduino Nano is frequently used in many breathing aid systems $[55,57$, $61,62]$ to control the signal received from other equipment. Different electronic devices sucg as multiplexer, comparator, oscillator, capacitor, D/A converter, MOSFET, 3D printer, digital display are used in oxygen therapy devices [38], ventilators [53, 54, 58], and CPAP devices [61]. AMBU bag is normally designed to be operated manually, but in some

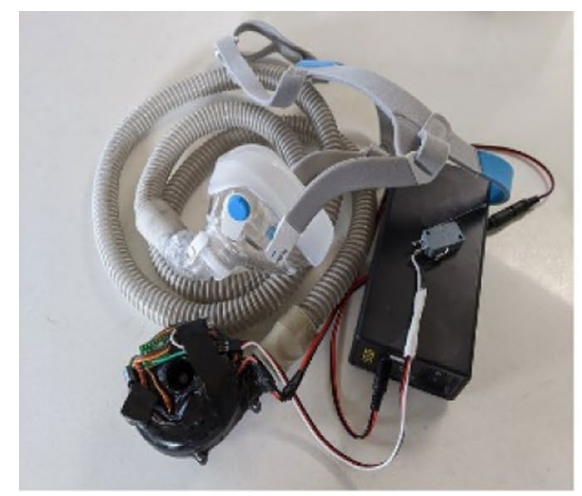

(a)

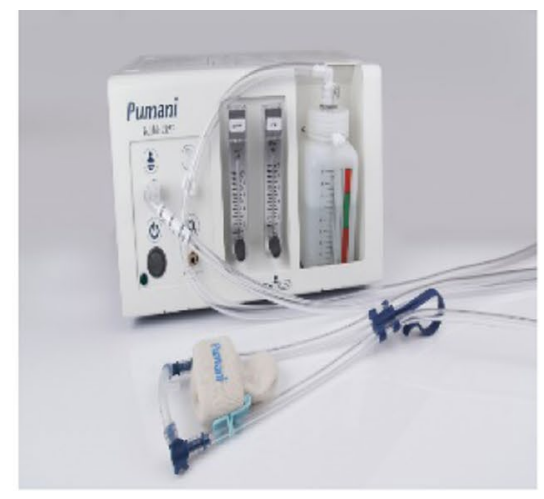

(b)

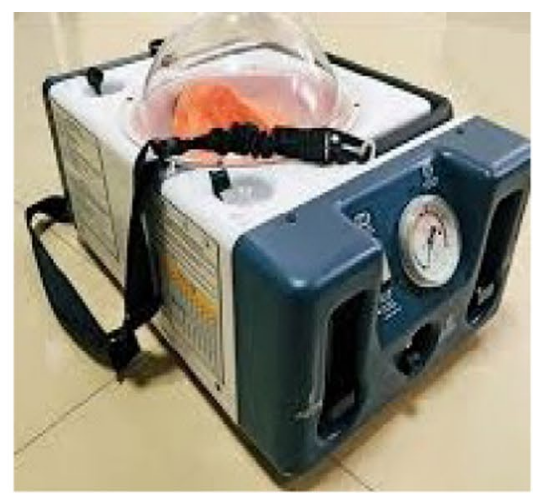

(c)

Fig. 4 CPAP devices for respiration support. a PAPR [62], b PUMANI bubbleCPAP [63], c Saans [65] 
Table 1 Comparative analysis of existing technologies available for breathing support

\begin{tabular}{|c|c|c|c|c|c|c|c|}
\hline $\begin{array}{l}\text { Breathing aid } \\
\text { devices }\end{array}$ & Cost & Technology used & Weight/Portability & $\begin{array}{l}\text { Coverage environ- } \\
\text { ment }\end{array}$ & $\begin{array}{l}\text { Case handled } \\
\text { in COVID-19 }\end{array}$ & Merits & Demerits/Risks \\
\hline Oxygen therapy & High & Medical & Heavy weight & $\begin{array}{l}\text { Hospital, Ambu- } \\
\text { lance }\end{array}$ & Acute & $\begin{array}{l}\text { Improve survival } \\
\text { rates }\end{array}$ & Fire risk \\
\hline Ventilator & Low & $\begin{array}{l}\text { Microcon- } \\
\text { troller, CAM, } \\
\text { Electronic, and } \\
\text { Mechanical }\end{array}$ & Light weight & $\begin{array}{l}\text { Home, Hospital, } \\
\text { Ambulance }\end{array}$ & Acute & $\begin{array}{l}\text { Comfortable, res- } \\
\text { piratory muscle } \\
\text { in rest }\end{array}$ & Infection in lungs \\
\hline CPAP & Low & $\begin{array}{l}\text { Microcontroller, } \\
\text { Electronic, and } \\
\text { Mechanical }\end{array}$ & Light weight & $\begin{array}{l}\text { Home, Hospital, } \\
\text { Ambulance }\end{array}$ & Mild & Emergency support & Dry nose \\
\hline
\end{tabular}

devices, it is operated mechanically or using CAM arm [52, 55]. Almost all of the devices can be used in a different environment like home, hospital, and ambulance. But some devices are specially developed for the hospital environment [46], and ambulance [51]. In COVID-19 disease, oxygen therapy and ventilator can provide better treatment in acute respiratory problems where CPAP is commonly used in mild cases as preliminary treatment. Recently several devices are developed only for handling COVID-19 patients [50-52, 61]. Oxygen therapy is used to improve survival rate [36] of patients though it has fire risk in contact with flame or smoke [48]. Among all of them, CPAP devices can provide emergency support in the primary stage of respiratory problems and a ventilator is the most comfortable device for use [52].

In this study, sufficient breathing aid devices are reviewed for COVID-19 patients. It is noticed that most of them are under development or in prototype only. There may have some lack of sufficient funds for significant progress in their development. Government or health-related organizations can provide proper funding to complete these underdeveloped projects. Besides, in electronic-based devices there are much instrumental errors in providing original signal or result. A proper selection of electronic devices may overcome this type of problem. In addition, it is important to produce more breathing supporting devices in a short time in this pandemic situation. Still, there is not enough technology or manufacturing method to do this in this lockdown situation due to maintaining social distance. In this circumstance, 3D-printing technology can play an important role in the mass production of such breathing aid devices.

\section{Conclusion}

The COVID-19 is still an ongoing pandemic that is creating a lot of crisis in all sectors for humanity all over the world. This outbreak aims at increasing the threat-benefit investigation of assessing the modality of breathing assistant for the infected patients. This paper overviews the recent available technologies that are frequently used for COVID-19 patients in hospitals, homes as well as the ambulance. The existing breathing aid devices are categorized into oxygen therapy devices, ventilators, and CPAP devices for proper demonstration. The devices are described in terms of working principle with construction, the equipment and technology used, cost, and relative analysis of merits and demerits throughout the paper. The current challenges of existing technologies with possible future trends are also outlined in this review. In this and future epidemics, there is a strong technological ability to mitigate respiratory support devices by utilizing modern small-scale technologies. The researchers with medical practitioners would provide an appropriate solution by developing necessary tools for the patients having breathingrelated problems.

Funding No funding sources.

\section{Compliance with Ethical Standards}

Conflict of interest On behalf of all authors, the corresponding author states that there is no conflict of interest.

\section{References}

1. COVID-19 Coronavirus Pandemic. 2020. https://www.world ometers.info/coronavirus/. Accessed 4 Aug 2020.

2. Iyengar K, Mabrouk A, Jain VK, Venkatesan A, Vaishya R. Learning opportunities from COVID-19 and future effects on health care system. Diabetes Metab Syndr Clin Res Rev. 2020;14:943-6. https://doi.org/10.1016/j.dsx.2020.06.036.

3. Ayon SI, Islam MM, Hossain MR. Coronary artery heart disease prediction: a comparative study of computational intelligence techniques. IETE J Res. 2020. https://doi.org/10.1080/03772 063.2020 .1713916 .

4. Islam MM, Iqbal H, Haque MR, Hasan MK. Prediction of breast cancer using support vector machine and K-Nearest neighbors. In: 2017 IEEE Region 10 Humanitarian Technology Conference (R10-HTC). IEEE, 2017; pp 226-229. 
5. Hasan MK, Islam MM, Hashem MMA. Mathematical model development to detect breast cancer using multigene genetic programming. In: 2016 5th International Conference on Informatics, Electronics and Vision (ICIEV). IEEE, 2016; pp 574-579.

6. Haque MR, Islam MM, Iqbal H, Reza MS, Hasan MK. Performance Evaluation of Random Forests and Artificial Neural Networks for the Classification of Liver Disorder. In: 2018 International Conference on Computer, Communication, Chemical, Material and Electronic Engineering (IC4ME2). IEEE, 2018; pp $1-5$.

7. Islam Ayon S, Milon Islam M. Diabetes prediction: a deep learning approach. Int J Inf Eng Electron Bus. 2019;11:21-7. https:// doi.org/10.5815/ijieeb.2019.02.03.

8. Islam MZ, Islam MM, Asraf A. A Combined Deep CNNLSTM network for the detection of novel coronavirus (COVID-19) using X-ray images. 2020; pp 1-20. https://doi. org/10.1101/2020.06.18.20134718.

9. Muhammad LJ, Islam MM, Usman SS, Ayon SI. Predictive data mining models for novel coronavirus (COVID-19) infected patients' recovery. SN Comput Sci. 2020;1:206. https://doi. org/10.1007/s42979-020-00216-w.

10. Wu Y-C, Chen C-S, Chan Y-J. The outbreak of COVID-19. J Chin Med Assoc. 2020;83:217-20. https://doi.org/10.1097/ JCMA.0000000000000270.

11. Namendys-Silva SA. Respiratory support for patients with COVID-19 infection. Lancet Respir Med. 2020;8:e18. https:// doi.org/10.1016/S2213-2600(20)30110-7.

12. Pons-Òdena M, Valls A, Grifols J, Farré R, Lasosa FJC, Rubin BK. COVID-19 and respiratory support devices. Paediatr Respir Rev. 2020. https://doi.org/10.1016/j.prrv.2020.06.015.

13. Pfeifer M, Ewig S, Voshaar T, Randerath WJ, Bauer T, Geiseler J, Dellweg D, Westhoff M, Windisch W, Schönhofer B, Kluge S, Lepper PM. Position paper for the state-of-the-art application of respiratory support in patients with COVID-19. Respiration. 2020. https://doi.org/10.1159/000509104.

14. Islam MM, Rahaman A, Islam MR. Development of smart healthcare monitoring system in IoT environment. SN Comput Sci. 2020;1:185. https://doi.org/10.1007/s42979-020-00195-y.

15. Rahaman A, Islam $M$, Islam $M$, Sadi $M$, Nooruddin S. Developing IoT based smart health monitoring systems: a review. Rev d'Intell Artif. 2019;33:435-40. https://doi.org/10.18280/ria.330605.

16. Islam MM, Sadi MS, Zamli KZ, Ahmed MM. Developing walking assistants for visually impaired people: a review. IEEE Sens J. 2019;19:2814-28. https://doi.org/10.1109/JSEN.2018.2890423.

17. Islam MM, Neom $\mathrm{NH}$, Imtiaz MS, Nooruddin S, Islam MR, Islam MR. A review on fall detection systems using data from smartphone sensors. Ing Des Syst d'Inform. 2019;24:569-76. https:// doi.org/10.18280/isi.240602.

18. Islam MM, Sadi MS, Braunl T. Automated walking guide to enhance the mobility of visually impaired people. IEEE Trans Med Robot Bionics. 2020. https://doi.org/10.1109/TMRB.2020.30115 01.

19. Khanom M, Sadi MS, Islam MM.A comparative study of walking assistance tools developed for the visually impaired people. In: 1st Int Conf Adv Sci Eng Robot Technol 2019, ICASERT 2019. 2019; pp:1-5. https://doi.org/10.1109/ICASERT.2019.8934566.

20. Nooruddin S, Milon Islam M, Sharna FA. An IoT based device-type invariant fall detection system. Internet Things. 2020;9:100130. https://doi.org/10.1016/j.iot.2019.100130.

21. Rahman MM, Islam MM, Ahmmed S, Khan SA. Obstacle and fall detection to guide the visually impaired people with real time monitoring. SN Comput Sci. 2020;1:219. https://doi.org/10.1007/ s42979-020-00231-x.

22. Alam N, Islam M, Habib A, Mredul MB. Staircase detection systems for the visually impaired people : a review. Int J Comput Sci Inf Secur. 2018;16:13-8.
23. Habib A, Islam MM, Kabir MN, Mredul MB, Hasan M. Staircase detection to guide visually impaired people: A hybrid approach. Rev d'Intell Artif. 2019;33:327-34. https://doi. org/10.18280/ria.330501.

24. Islam MM, Sadi MS (2018) Path Hole Detection to Assist the Visually Impaired People in Navigation. In: 2018 4th International Conference on Electrical Engineering and Information \& Communication Technology (iCEEiCT). IEEE, 2018; pp 268-273.

25. Kamal MM, Bayazid AI, Sadi MS, Islam MM, Hasan N. Towards developing walking assistants for the visually impaired people. In: 2017 IEEE Region 10 Humanitarian Technology Conference (R10-HTC). IEEE, 2017; pp 238-241.

26. Islam MM, Sadi MS, Islam MM, Hasan MK. A New Method for Road Surface Detection. In: 2018 4th International Conference on Electrical Engineering and Information \& Communication Technology (iCEEiCT). IEEE, 2018; pp 624-629.

27. Rezwanul Haque M, Milon Islam M, Saeed Alam K, Iqbal H. A computer vision based lane detection approach. Int J Image Graph Signal Process. 2019;11:27-34. https://doi.org/10.5815/ ijigsp.2019.03.04.

28. Rahman MM, Islam M, Ahmmed S. "BlindShoe": an electronic guidance system for the visually impaired people. J Telecommun Electron Comput Eng. 2019;11:49-54.

29. Rahman MA, Sadi MS, Islam MM, Saha P. Design and development of navigation guide for visually impaired people. In: 2019 IEEE International Conference on Biomedical Engineering, Computer and Information Technology for Health (BECITHCON). IEEE, 2019; pp 89-92.

30. McEnery T, Gough C, Costello RW. COVID-19: respiratory support outside the intensive care unit. Lancet Respir Med. 2020;8:538-9. https://doi.org/10.1016/S2213-2600(20)30176-4.

31. Dondorp AM, Hayat M, Aryal D, Beane A, Schultz MJ. Respiratory support in COVID-19 patients, with a focus on resourcelimited settings. Am J Trop Med Hyg. 2020;102:1191-7. https:// doi.org/10.4269/ajtmh.20-0283.

32. Iyengar K, Bahl S, Vaishya Raju, Vaish A. Challenges and solutions in meeting up the urgent requirement of ventilators for COVID-19 patients. Diabetes Metab Syndr Clin Res Rev. 2020;14:499-501. https://doi.org/10.1016/j.dsx.2020.04.048.

33. Pearce JM. A review of open source ventilators for COVID19 and future pandemics. F1000Research. 2020;9:10.12688/ f1000research.22942.2.

34. Radovanovic D, Rizzi M, Pini S, Saad M, Chiumello DA, Santus P. Helmet CPAP to treat acute hypoxemic respiratory failure in patients with COVID-19: a management strategy proposal. J Clin Med. 2020;9:1191. https://doi.org/10.3390/jcm9041191.

35. (2020) Airway management of COVID-19 patients with severe pneumonia. Zhonghua Er Bi Yan Hou Tou Jing Wai Ke Za Zhi. https://doi.org/10.3760/cma.j.issn.1673-0860.2020.04.001.

36. Ahmadi Z, Sundh J, Bornefalk-Hermansson A, Ekström M. Longterm oxygen therapy $24 \mathrm{vs} 15 \mathrm{~h} /$ day and mortality in chronic obstructive pulmonary disease. PLoS One. 2016;11:e0163293. https://doi.org/10.1371/journal.pone.0163293.

37. Hui DS, Chow BK, Lo T, Ng SS, Ko FW, Gin T, Chan MTV. Exhaled air dispersion during noninvasive ventilation via helmets and a total facemask. Chest. 2015;147:1336-43. https://doi. org/10.1378/chest.14-1934.

38. Cereceda-Sánchez F, Molina-Mula J. Capnography as a tool to detect metabolic changes in patients cared for in the emergency setting. Rev Lat Am Enfermagem. 2017. https://doi. org/10.1590/1518-8345.1756.2885.

39. Herren T, Achermann E, Hegi T, Reber A, Stäubli M. Carbon dioxide narcosis due to inappropriate oxygen delivery: a case report. J Med Case Rep. 2017. https://doi.org/10.1186/s1325 6-017-1363-7. 
40. Whittle JS, Pavlov I, Sacchetti AD, Atwood C, Rosenberg MS. Respiratory support for adult patients with COVID-19. J Am Coll Emerg Phys Open. 2020;1:95-101. https://doi.org/10.1002/ emp2.12071.

41. Farias E, Rudski L, Zidulka A. Delivery of high inspired oxygen by face mask. J Crit Care. 1991;6:119-24. https://doi. org/10.1016/0883-9441(91)90002-B.

42. Okuda M, Kashio M, Tanaka N, Matsumoto T, Ishihara S, Nozoe T, Fujii T, Okuda Y, Kawahara T, Miyata K. Nasal high-flow oxygen therapy system for improving sleep-related hypoventilation in chronic obstructive pulmonary disease: a case report. J Med Case Rep. 2014;8:341. https://doi.org/10.1186/1752-1947-8-341.

43. Rochwerg B, Granton D, Wang DX, Helviz Y, Einav S, Frat JP, Mekontso-Dessap A, Schreiber A, Azoulay E, Mercat A, Demoule A, Lemiale V, Pesenti A, Riviello ED, Mauri T, Mancebo J, Brochard L, Burns K. High flow nasal cannula compared with conventional oxygen therapy for acute hypoxemic respiratory failure: a systematic review and meta-analysis. Intensive Care Med. 2019. https://doi.org/10.1007/s00134-019-05590-5.

44. Nishimura M. High-flow nasal cannula oxygen therapy in adults: physiological benefits, indication, clinical benefits, and adverse effects. Respir Care. 2016;61:529-41. https://doi.org/10.4187/ respcare.04577.

45. Lin Y, Zhang X, Li L, Wei M, Zhao B, Wang X, Pan Z, Tian J, Yu W, Su D. High-flow nasal cannula oxygen therapy and hypoxia during gastroscopy with propofol sedation: a randomized multicenter clinical trial. Gastrointest Endosc. 2019;90:591-601. https ://doi.org/10.1016/j.gie.2019.06.033.

46. Global Hyperbaric Oxygen Therapy Devices Market 2020 by Manufacturers, Regions, Type and Application, Forecast to 2025. 2020. https://www.researchstore.biz/report/global-hyperbaric -oxygen-therapy-devices-market-11401. Accessed 7 July 2020.

47. Lam G, Fontaine R, Ross F, Chiu E. Hyperbaric oxygen therapy: exploring the clinical evidence. Adv Skin Wound Care. 2017;30:181-90. https://doi.org/10.1097/01.ASW.0000513089 .75457 .22 .

48. Ustad F, Ali F, Ustad T, Aher VMCP, Suryavanshi H. Uses OF hyperbaric oxygen therapy: a review. J Evol Med Dent Sci. 2012;1:892-906. https://doi.org/10.14260/jemds/144.

49. Smith A, Marshall B, Bennett N, Arthur B, Dickman M. PURL: supplemental oxygen: more isn't always better. J Fam Pract. 2019;68:E10-1.

50. NASA, Ventilator Intervention Technology Accessible Locally. 2020. https://www.nasa.gov/press-release/nasa-developed-venti lator-authorized-by-fda-for-emergency-use. Accessed 5 July 2020.

51. mboVent and Medtronic COVID-19 Ventilators Open Sourced. 2020. https://members.smoove.io//view.ashx?message=h4474 $1568 \mathrm{O} 122392748 \mathrm{O} 219654 \mathrm{O} 122323322 \& \mathrm{r}=1009$. Accessed 5 July 2020.

52. MIT, MIT Emergency Ventilator Project. 2020. https://emergencyvent.mit.edu/. Accessed 5 July 2020.

53. Lu S, Lin H, Kuo H, Wu C, Wu W, Chen C, Liao Y. Design and study of a portable high-frequency ventilator for clinical applications. In: 2019 41st Annual International Conference of the IEEE Engineering in Medicine and Biology Society (EMBC). IEEE, 2019; pp 2353-2356.

54. Shahid M. Prototyping of Artificial Respiration Machine Using AMBU Bag Compression. In: 2019 International Conference on
Electronics, Information, and Communication (ICEIC). Institute of electronics and information engineers (IEIE), 2019; pp 1-6.

55. Islam R, Ahmad M. Designing an Electro-Mechanical Ventilator Based on Double CAM Integration Mechanism. In: 2019 1st International Conference on Advances in Science, Engineering and Robotics Technology (ICASERT). IEEE, 216; pp 1-6.

56. Jürß H, Degner M. A new compact and low-cost respirator concept for one way usage. IFAC-PapersOnLine. 2018;51:367-72. https:// doi.org/10.1016/j.ifacol.2018.11.612.

57. Garmendia O, Rodríguez-lazaro MA, Otero J, Phan P, Stoyanova A, Dinh-xuan AT, Gozal D, Navajas D, Farré R. Lowcost, easy-to-build noninvasive pressure support ventilator for under-resourced regions: open source hardware description, performance and feasibility testing. Eur Respir J. 2020. https://doi. org/10.1183/13993003.00846-2020.

58. Mohsen A, Husseini A, Lee HJ, Negrete J, Powelson S, Servi A, Slocum A, Saukkonen J. Design and Prototyping of a Lowcost Portable Mechanical Ventilator. Trans ASME-W-J Med Dev. 2010; 4(2)1-9.

59. Fuchs P, Obermeier J, Kamysek S, Degner M, Nierath H, Jürß H, Ewald H, Schwarz J, Becker M, Schubert JK. Safety and applicability of a pre-stage public access ventilator for trained laypersons : a proof of principle study. BMC Emerg Med. 2017. https://doi. org/10.1186/s12873-017-0150-5.

60. Fogarty M, Orr J, Westenskow D, Brewer L, Sakata D. Electric Blower Based Portable Emergency Ventilator; Utah Space Grant Consort: 2013.https://digitalcommons.usu.edu/spacegrant/2013/ Session4/2. Accessed 5 July 2020.

61. Akhand MAH. Indigenously developed CPAP device to support Covid-19 patients. 2020. https://www.observerbd.com/news. php?id=260379. Accessed 4 July 2020.

62. Low-Cost Open-Source Ventilator-ish Device or PAPR. 2020. https://github.com/jc15m1/ventilator. Accessed 4 July 2020.

63. PUMANI bubbleCPAP A low-cost respiratory device for newborns and children. 2020. http://hadleighhealthtechnologies.com/ pumani-bcpap/. Accessed 4 July 2020.

64. Dundek M, Mollazadeh-Moghaddam K, Bellare A, Burke T, Sharma R, Owuor J. Ultra-low-cost, high quality bubble CPAP for low resource settings. In: 2019 IEEE Global Humanitarian Technology Conference (GHTC). IEEE, 2019; pp 1-2.

65. Gehlot Y, Kumar MB, Prasad G, Shetty S, Senthil A, Deval N, Jangir NK, Vijayrajan A. Validation of an infrastructure independent cpap for newborns suffering from respiratory distress syndrome. In: 2020 International Conference on COMmunication Systems \& NETworkS (COMSNETS). IEEE, 2020; pp 76-81.

66. Mukkundi BK, Prasad G, Gehlot Y, Deval N, Jangir NK, Shetty S, Babu GG, AS N, Kakani VK, Tauheed A. Implementation of conventional air-oxygen blending in multi-powered continuous positive airway pressure (CPAP) Device. In: 2019 11th International Conference on Communication Systems \& Networks (COMSNETS). IEEE, 2019; pp 807-812.

Publisher's Note Springer Nature remains neutral with regard to jurisdictional claims in published maps and institutional affiliations. 